\title{
LA REGISTRACIÓN* CIVIL COMO GARANTÍA DEL DERECHO HUMANO A LA IDENTIDAD Y A LA FAMILIA
}

\author{
CIVIL REGISTRATRION AS A GUARANTEE OF HUMAN RIGHT TO \\ IDENTITY AND FAMILY
}

Mariana Manso ${ }^{1}$

(Argentina)

\section{Resumen.}

La definición de un registro civil universal -acuñada en la modernidadestablece que es la base para que los estados puedan tener información precisa de su población y así poder elaborar sus planes de desarrollo social y económico.

La relación entre las personas, la familia y la institución "registro civil" es íntima y permanente; nacemos, convivimos, nos casamos y nos morimos y todos son hechos - actos "civiles" y "familiares" que pasan por ante el Registro Civil.

La familia y los vínculos filiales deben recibir especial protección de los órganos del estado y en especial el registro civil que es un eslabón fundamental en la protección de nuestra identidad, la intangibilidad de los cuerpos y la diversidad de las personas.

Palabras Claves: identidad, familia, filiación, Registro Civil.

\begin{abstract}
The definition of a universal 'civil registry' (a.k.a vital statistics office) - coined in modernity - establishes that this is the basis for States to have accurate information of their populations and thus to be able to elaborate their social and economic development plans.

The relationship among people, family, and 'civil registry' is intimate and permanent, people are born, coexist, marry, and die and all these are "civil" and "family" facts acts recorded with the Civil Registry.

The family and the filial bonds must receive special protection from the government bodies and, especially, the 'civil registry' which is a fundamental link in the protection of people's identity, intangibility of bodies, and diversity.
\end{abstract}

Keywords: identity, family, filiation, Civil Registry.

\footnotetext{
Término utilizado en el idiolecto jurídico propio de Argentina.

1 Abogada del Estado Argentino. Docente de la Universidad Nacional de la Plata-Facultad de Ciencias Jurídicas y Sociales.
} 


\section{REGISTRO CIVIL E IDENTIDAD.}

El Registro civil es la institución a quien el estado le encomienda la documentación del estado civil de las personas. Para ello, se sustenta jurídicamente en normas de derecho registral Civil que regulan la publicidad del estado civil a través de asientos registrales, de normas de carácter puramente administrativo que se amalgaman con el derecho material y privado que delimita su propio contenido.

Esta institución nacida en un contexto social marcado por el liberalismo, determinó y legitimó la intromisión del Estado en la esfera privada de las personas: control de la natalidad al exigir la registración de los nacimientos, control de la conformación de la familia a través del matrimonio como única forma socialmente aceptada como correcta y control de las muertes a través de las actas de defunción.

$\mathrm{Su}$ génesis institucional obedeció a cuestiones sanitarias y estadísticas, planificación de políticas públicas y asociado a una misión de control y normalización de las relaciones interpersonales y familiares; pero paradójicamente -contrario al pensamiento de muchos operadores jurídicos y registrales- en la actualidad se ha convertido en un garante de la desemejanza y de las diferencias a través de los instrumentos que expide y acreditan la identidad de las personas.

Luego de la reforma constitucional del año 1994 en la República Argentina -al incorporar los tratados internacionales de derechos humanos con jerarquía constitucional- se produce en el funcionamiento de esta institución un proceso -ahora ineludible- de transversalización de los derechos humanos que impactan en todas las áreas y niveles: legislación, políticas públicas y programa de todo nuestro derecho interno.

Proceso que se acentúa y se visualiza positivamente con la entrada en vigencia del Código Civil y Comercial en el año $2015^{2}$, pues la télesis de este cuerpo y su técnica legislativa influyen directamente en la actividad de los registros.

El Registro Civil no puede ser visto como mero reproductor de hechos civiles de las personas; por el contrario, es la receptora primaria de las

Aprobado por Ley $\mathrm{N}^{\circ} 26.994$ del $1^{\circ}$ de octubre de 2014 . 
peticiones de los particulares vinculadas a su derecho a la identidad y para ello deberá tener al individuo como centro de toda la actividad registral.

El Estad o reconoce a la familia como centro de realización de la persona y es allí donde la actividad registral cobra importancia y trascendencia pues con los instrumentos que confecciona - actas - debe garantizar el efectivo goce de los derechos que hacen a la identidad e integridad humanas.

\section{a) El Derecho a la Identidad.}

La falta de reconocimiento de la identidad puede implicar que la persona no cuente con constancia legal de su existencia o que cuente con una identidad vulnerada o disminuida, dificultando el pleno ejercicio de sus derechos civiles, políticos, económicos, sociales y culturales, así como la realización de su proyecto personal de vida.

Realización del proyecto personal de vida pues los nuevos grupos sociales configurados aclaman por el reconocimiento a su identidad (Relatoría sobre los derechos de las personas LGBTI de la Comisión Interamericana de Derechos Humanos, OEA).

El registro civil debe encontrar los mecanismos administrativos por los cuales garantice a todas las personas, el efectivo goce del derecho a la identidad.

Estos desafíos no pueden ser meras expresiones de deseo sino que deben ser políticas de Estado; un Estado y un sistema que se implementen no como vigilador o persecutorio de las distintas personas, a través de la identidad, sino que los apoye, los apruebe y les dé la posibilidad de ejercer sus derechos en una cultura de respeto al ser humano y a su proyecto personal.

\section{b) El sistema argentino de identificación civil.}

En Argentina rige la Ley $\mathrm{N}^{\circ} 26.413$ de "REGISTRO DEL ESTADO CIVIL Y CAPACIDAD DE LAS PERSONAS". Su artículo 1ำ establece "Todos los actos o hechos que den origen, alteren o modifiquen el estado civil y la capacidad de las personas, deberán inscribirse en los correspondientes registros de las provincias, de la Nación y de la Ciudad Autónoma de Buenos Aires. Corresponde al Registro del Estado Civil y Capacidad de las Personas, proporcionar los datos necesarios para que se elaboren las estadísticas vitales, correspondientes a nacimientos y defunciones, defunciones de niños menores de un año, defunciones fetales, matrimonios, divorcios, filiaciones y adopciones" $y$ su artículo $2^{\circ}$ "El Registro del Estado Civil y Capacidad de las Personas será organizado por los gobiernos provinciales y de la Ciudad Autónoma 
de Buenos Aires y estará a cargo de un director general, el que deberá poseer título de abogado.

De ello se desprende la existencia y funcionamiento de un SISTEMA DE IDENTIFICACIÓN ARGENTINO encargado de la Identificación Civil entendida como la actividad por la cual el Estado selecciona una serie de atributos propios y distintivos y otras circunstancias de una persona que permiten individualizarla de modo único, inequívoco y diferenciable de los demás a fin de poder garantizarle el ejercicio de todos sus derechos y cumplimiento de sus obligaciones.

A su vez, este sistema argentino de identificación civil, funciona a través de dos subsistemas:

1) El REGISTRAL: de competencia exclusiva de las provincias en cuanto a su ejecución, siendo responsables del registro de los hechos y actos vitales.

2) El IDENTIFICATORIO: de carácter exclusivo y excluyente federal regido por las leyes $\mathrm{N}^{\mathrm{o}} 17.711$ (Identificación registro y clasificación potencial humano nacional) y № 24.540 (Régimen de identificación de los recién nacidos aprobación). Este sistema es la base para la confección del padrón electoral nacional de acuerdo a lo previsto en la Ley № 26.571 (Partidos políticos ley de democratización de la representación política, la transparencia y la equidad electoral).

La actividad registral eficiente, trae ineludiblemente beneficios para el derecho a la identidad, pues al contar con datos e información certera respecto a la población, impactará en una mejora en los gastos públicos, en una mejor programación del gasto, en una mejora en la efectividad de programas sociales y políticas públicas en general que identifiquen a la población vulnerable.

Un sistema de identidad debe tener como objetivos centrales: verificar la identidad y contar con un sistema de registro universal eficiente y efectivo, implementación de plataformas tecnológicas, fortalecimiento de recursos humanos a través de planes permanentes de capacitación.

Argentina desde el año 2016 se encuentra bajo un nuevo paradigma del Estado con el Decreto $N^{\circ}$ 434/2016 que aprobó el "Plan de Modernización del Estado" que impulsa formas de gestión con desarrollo de tecnologías aplicadas a la administración pública central y descentralizada, que acerquen al ciudadano a la gestión del Gobierno y mejore las capacidades del Estado. 
Esto obliga a los gobiernos provinciales a implementar el Registro Digital de las Personas como herramienta informática que producirá actas digitales y permitirá la generación, tramitación y guarda de todos los documentos respaldatorios de las mismas, pasando de este modo al paradigma de la identidad electrónica.

\section{c) Registro Civil y la meta relativa a la identidad y los ODS}

La agenda para el desarrollo después de 2015 (Agenda 2030), tiene entre sus metas, la 16.9 de los $\mathrm{ODS}^{3}$ la siguiente: "proporcionar acceso a una identidad jurídica para todos, en particular mediante el registro de nacimientos".

Donde radica la importancia de esta meta, en que los estados que en mayor medida garanticen esta meta, estarán coadyuvando a la consecución de por lo menos otros 10 ODS .

A través de estos objetivos de desarrollo se ve el impacto que tiene la identidad y los sistemas de identificación, pues aquel que carece de papeles "...para mostrar cuando nos pregunten quiénes somos es el menor de los derechos humanos (porque la identidad social es un derecho primario) aunque es también el más importante (porque las leyes exigen que de ese papel dependa la inserción del individuo en la sociedad)..."4 .

Por ello, los estados tienen que reforzar esfuerzos en presentar servicios y ofrecer oportunidades a los ciudadanos que garanticen su derecho a la identidad, como el uso de plataformas móviles de carácter digital para recibir documentos de identidad: actas, certificados, documentos nacionales de identidad, pasaporte, cédulas, etc.

La reforma constitucional del año 1994 al incorporar los tratados internacionales de derechos humanos con jerarquía constitucional produce una transversalización (proceso por el cual los derechos humanos impactan en todas las áreas y niveles, legislación políticas públicas y programas) en todo nuestro derecho interno.

Meta 1.3 de los ODS: Protección social, incluso para los más vulnerables. Meta 1.5 de los ODS: Asistencia para hacer frente a las crisis y los desastres. Meta 1.4 de los ODS: Acceso de los pobres a los recursos económicos, incluidos los bienes y el financiamiento, Metas 5.A y 5.B de los ODS: Empoderamiento de la mujer. Meta 3.2 de los ODS: Poner fin a las muertes evitables de recién nacidos. Meta 12.C de los ODS: Aumentar la eficiencia energética y eliminar subsidios a la energía perniciosos.

Meta 10.C de los ODS: Reducir los costos de las remesas. Meta 16.5 de los ODS: Reducir la corrupción. Meta 16.A de los ODS: Combatir la delincuencia y el terrorismo.

4 Carta Abierta a la Solidaridad José Saramago. Lisboa 3-12-98. 
Este proceso, es aún muy lento pues los derechos humanos debieran ser nuestro faro en cualquier resolución de conflictos en los que se encuentre involucrado un ser humano (laboral, penal, de familia, administrativo, etc). Nuestro estado ha podido avanzar, como es el caso de las políticas públicas del Estado Nacional en materia de iniciativa legislativa que sancionaron normas referidas a la ampliación de derechos y con ello la incorporación de nuevos grupos sociales como sujetos de derecho, estas normas son:

- Ley de Promoción y Protección de los Derechos del Niño 26.061 de octubre de 2005 y la Ley Provincial N 13.298 (cambio de paradigma de protección el niño como sujeto y no como objeto de protección);

- Ley de Matrimonio Igualitario $\mathrm{N}^{\circ} 26.618$ del 23 de julio 2010;

- Ley de Identidad de Género $\mathrm{N}^{\circ} 26.743$ del 24 de mayo 2012 en Provincia Ley $\mathrm{N}^{\circ} 14.595$ art 122 "Informara los cambios a los Organismos que registralmente se determinen";

- LeydeReproducciónmédicamenteasistidaN²6.862del5dejuniode2013;y

- recientemente sancionado Código Civil y Comercial de la Nación Ley $\mathrm{N}^{\circ}$ 26.994 del $1^{\circ}$ octubre de 2014.

La transversalización impacta directamente sobre la actividad de los registros civiles en el que se amalgaman normas de carácter puramente administrativo, registrales y especialmente con las normas referidas al estado civil y capacidad de las personas.

El registro hace efectivo el ejercicio del derecho a la identidad que junto con la vida y la libertad conforman una trilogía de intereses que pueden calificarse como esenciales y por ello, reciben una privilegiada y eficaz tutela jurídica ${ }^{5}$, tal como lo establecen los estándares internacionales de derechos humanos.

La reforma del Código civil y especialmente los capítulos referidos a la familia, impactan directamente sobre los registros en Argentina y vamos a trabajar sobre los mismos paradigmas que plantea esta nueva legislación y que el Derecho registral hace suyo: la persona como centro de toda la actividad Registral. Se debe garantizar a través de la registración el efectivo goce de sus derechos, entendiendo que la persona es ella con respecto a sus relaciones familiares.

Fallo del Juzgado Civ. y Com. Paraná, N 4, 15/9/2003, “Z., H. M. v. C., J. R. y otros”. 


\section{PROTECCIÓN DE LA FAMILIA EN EL ORDENAMIENTO JURÍDICO DE ARGENTINA.}

En la Constitución Nacional Argentina, la familia encuentra protección a través del artículo 14 bis al señalar que el Estado debe asegurar “... la protección integral de la familia; la defensa del bien de familia; la compensación económica familiar y el acceso a una vivienda digna".

Se reconoce a la familia como primer nivel de integración social del individuo (socialización primaria) transmisor de cultura y lugar de desarrollo personal.

A través de la legislación, decisiones administrativas y sentencias judiciales, se ha ampliado la clásica concepción de familia nuclear, heterosexual como ideal cultural, a una multiplicidad de formas de familia: homoparentales, conformaciones familiares múltiples. ( Ferrari G. y Manso, M., 2015)

El Código Civil y Comercial materializa como derecho positivo a la Constitución Nacional y con ella a los tratados de Derechos Humanos, no solo como fuente del derecho sino como carta política: "ARTICULO $1^{\circ}$.Fuentes y aplicación. Los casos que este Código rige deben ser resueltos según las leyes que resulten aplicables, conforme con la Constitución Nacional y los tratados de derechos humanos en los que la República sea parte. A tal efecto, se tendrá en cuenta la finalidad de la norma. Los usos, prácticas y costumbres son vinculantes cuando las leyes o los interesados se refieren a ellos o en situaciones no regladas legalmente, siempre que no sean contrarios a derecho".

La Constitución Nacional, los Tratados y las opiniones y sentencias de los órganos internacionales y de la Corte Suprema de Justicia de la Nación, han impactado directamente en cuestiones de familia, porque por ejemplo la $\mathrm{CIDH}$ ha dicho:

1. en el caso Atala Rifo con respecto a que la orientación sexual no puede ser motivo de discriminación en el ámbito del derecho de familia;

2. en el caso Atavia Murillo vs Costa Rica en lo que hace al acceso integral a la técnicas de reproducción humana asistida;

3. en el caso Forneron vs Argentina donde ha establecido que hay un concepto de familia convencional totalmente pluralista y que no admite ningún tipo de discriminación en lo que se entiende por familia. 
Esto genera un cambio en la interpretación y la aplicación del Código Civil y Comercial, en las relaciones de familia y su protección a través de la registración.

A estas directrices, por ser el Registro Civil un órgano del Estado, debemos sumarle un principio fundamental ligado a la actuación de las instituciones del Estado que es la Tutela Judicial o ADMINISTRATIVA EFECTIVA (art. 15 Constitución de la Provincia de Buenos Aires). Consistente en acciones positivas tendientes a promover derechos fundamentales de las personas, fomentar la dignidad humana de modo tal que las actuaciones administrativas armonicen criterios de objetividad, imparcialidad, justicia y equidad, ello prestado en un plazo oportuno y razonable.

En este contexto, la concreta aplicación de las normas civiles, registrales y administrativas deben tener como faro el prisma de los Derechos Humanos.

Ello pues, sabido es que la realidad en los casos particulares va a superar a las previsiones legislativas, porque nunca toda la realidad puede ser anticipada y entonces las personas no pueden esperar que opere un cambio legislativo, para que el ejercicio de sus derechos pueda ser reconocido en un tiempo oportuno y razonable.

Por eso, será fundamental el rol de los operadores jurídicos integrando, armonizando, ponderando y prestando especial atención a las circunstancias particulares de cada caso, de manera tal de lograr soluciones justas que protejan el derecho a la identidad y las relaciones de familia. ${ }^{6}$

\section{FUENTES DE FILIACIÓN EN EL NUEVO CÓDIGO CIVIL Y COMERCIAL.}

El viejo régimen filiatorio del Código Civil de Vélez Sarsfield, era patriarcal, heteronormativo y liberal; es decir, que solo admitía la existencia de un doble vínculo, la diversidad de sexo (binomio hombre-mujer) de los progenitores y daba por sentado la coincidencia entre la filiación formal y la biológica.

Es decir, quehistóricamente existió un entramado familiar uniforme, en donde los lazos filiatorios giraban en torno al reconocimiento de la paternidad: el

Artículo 8 de la Convención sobre los Derechos del Niño, el derecho a la identidad comprende, entre otros, el derecho a las relaciones de familia. 
vínculo filial materno estaba protegido por el alumbramiento y el paterno por el matrimonio o el reconocimiento posterior del hombre. Una concepción biologicista de las relaciones humanas y de la procreación humana.

Este modo de considerar las relaciones de familia ha sido socavado por la realidad: la ciencia generó la posibilidad de que ocurra la reproducción humana sin que existan relaciones sexuales.

En efecto, el desarrollo y perfeccionamiento de las técnicas de procreación asistida, la sanción de la Ley de Técnicas de Reproducción Humana Asistida $\mathrm{N}^{\circ}$ 26.862, que garantiza el acceso integral a los procedimientos y técnicas médico-asistenciales de reproducción médicamente asistida, junto con la aprobación de la Ley de Matrimonio igualitario $\mathrm{N}^{\circ} 26.618$, dio por tierra con el modelo tradicional de familia heterosexual. Estas leyes significaron el reconocimiento de nuevos sujetos de derecho y por ende la necesidad de incorporación de nuevos derechos.

Los cambios legislativos en Argentina, han producido una revolución en el campo de la filiación, poniendo en crisis principios que antes eran considerados incuestionables. Los cambios legislativos siempre llegan tarde y a reconocer situaciones sociales preexistentes, de lo contrario el derecho sería disciplinador y antidemocrático.

Asistimos una crisis ${ }^{7}$ en el derecho filial tradicional, edificado exclusivamente sobre la base de los conceptos de maternidad y paternidad, para incorporar nociones que realzan la voluntad procreacional por encima del sexo de quienes llevan adelante los roles de crianza a través de la responsabilidad parental compartida, operando lo que los autores del nuevo Código definen como democratización de las relaciones familiares.

\section{a) Tipos de filiación}

Haciéndose eco de estas nuevas cuestiones aportadas por la realidad misma, el nuevo Código Civil y Comercial cambia el régimen filial, reconociendo tres fuentes, y consagrando el principio de igualdad entre ellas. La filiación por adopción plena, por naturaleza o por técnicas de reproducción humana asistida (en adelante TRHA), matrimonial y extramatrimonial, surten los mismos efectos.

RAE: crisis. Del lat. crisis, y este del gr. крıбıs krísis.1. f. Cambio profundo y de consecuencias importantes en un proceso o una situación, o en la manera en que estos son apreciados. 
- FILIACIÓN POR NATURALEZA: se mantiene prácticamente inalterable con respecto a la anterior legislación. Aquí el elemento biológico es el bastión para determinar la filiación. El Código Civil y Comercial establece que la determinación de la maternidad, el binomio de "quien dio a luz y el nacido" del siguiente modo: "ARTÍCULO 565.- Principio general. En la filiación por naturaleza, la maternidad se establece con la prueba del nacimiento y la identidad del nacido".

- FILIACIÓN POR ADOPCIÓN: expresa en elCódigo Civil y Comercial, "ARTÍCULO 594.- Concepto. La adopción es una institución jurídica que tiene por objeto proteger el derecho de niños, niñas y adolescentes a vivir y desarrollarse en una familia que le procure los cuidados tendientes a satisfacer sus necesidades afectivas y materiales, cuando éstos no le pueden ser proporcionados por su familia de origen. La adopción se otorga sólo por sentencia judicial y emplaza al adoptado en el estado de hijo, conforme con las disposiciones de este Código".

El anterior Código Civil contemplaba el instituto de la adopción a través de dos modalidades: simple y plena. El actual Código incorpora un nuevo tipo de adopción, que se denomina "adopción de integración", respondiendo así a una realidad social vigente en nuestro país.

Este instituto "no está orientado a amparar a un niño abandonado, sino a su incorporación a una familia en la que su padre o madre han contraído matrimonio (o unión convivencial) y desean que ese hijo de uno de ellos sea un hijo común, un hijo de ambos para integrar o constituir una única familia en lo jurídico porque seguramente - ya la constituyen en la práctica"8.

La adopción de integración no excluye ni extingue vínculos, sino al contrario, los amplía mediante la integración de una persona a un grupo familiar ya existente, al que un niño o adolescente conforma con su progenitor.

Tampoco está orientado a amparar a un niño abandonado, sino a su incorporación a una familia en la que su padre o su madre desean que ese hijo de uno de ellos sea un hijo común, un hijo de ambos para integrar o constituir una única familia en lo jurídico, porque en la práctica lo constituyen.

Pero la mayor ampliación de derechos fue al hacer extensivo este instituto a las conformaciones familiares múltiples: El registro Civil ha debido tomar nota de mandas judiciales que admiten este instituto y ordenan inscribir a los niños o niñas con "triple filiación" ${ }^{\prime \prime}$ un niño con doble vínculo

CNCiv., Sala C, 1-6-2000, E.D. 1888-688, citado en Colección Temática Derecho de Familia № 4, Filiación adoptiva, Juris, Rosario, 2005, Jurisprudencia temática, p. 277.

Idem Cita $\mathrm{N}^{\circ} 4$ 
filial al que se le incorpora un tercer vínculo por adopción integrativa y asimismo ordena modificar su apellido de manera tal que su conformación sea con tres apellidos correspondiendo cada uno de ellos a sus padres. ${ }^{10}$

- $\quad$ FILIACIÓN POR TÉCNICAS DE REPRODUCCIÓN HUMANA ASISTIDA: sienta sus cimientos en la ciencia médica y en el elemento volitivo. "ARTÍCULO 562.- Voluntad procreacional. Los nacidos por las técnicas de reproducción humana asistida son hijos de quien dio a luz y del hombre o de la mujer que también ha prestado su consentimiento previo, informado y libre en los términos de los artículos 560 y 561, debidamente inscripto en el Registro del Estado Civil y Capacidad de las Personas, con independencia de quién haya aportado los gametos"

El nuevo texto regula algunas cuestiones referentes a las prácticas de reproducción humana, dejando otras para la legislación especial. Una de ellas define a las prácticas como aquellos procedimientos y técnicas realizados con asistencia médica para la consecución de un embarazo (art. $2^{\circ}$ Ley $\mathrm{N}^{\mathrm{a}}$ 26.862). Existe un gran vacío legislativo de regulación del alcance, los derechos y las relaciones jurídicas derivadas del empleo de las TRHA, por ejemplo, cuestiones relativas al límite a la edad para el aporte, controles previos a los aportantes, definición de centro de salud, carácter no lucrativo del aporte de gametos, rescindibilidad del contrato y destino de los gametos, limite al aporte de gametos para un máximo de 6 personas o parejas, confidencialidad, uso futuro en caso de enfermedad, tiempo de conservación, destino del material genético, prohibición de elección fenotípica de gametos o embriones, protección del embrión no implantado.

El Código Civil y Comercial recepta en sentido amplio tanto a las técnicas homólogas -material genético proveniente de la pareja que presta el consentimiento- $y$ las técnicas heterólogas -cuando se acude a la donación de un tercero-. De esta manera, se armoniza lo estipulado en la ley especial, y al estándar impuesto por la Corte Interamericana de DD.HH. en el precedente "ARTIVIA MURILLO" del 28/11/2012, en cuanto al reconocimiento del acceso a los beneficios de estas técnicas como un derecho humano.

a)

\section{REGISTRACIÓN DE LA FUENTE DE FILIACIÓN POR TRHA}

Como hemos dicho, en la filiación por naturaleza, se prioriza el elemento genético, mientras que tanto en la filiación adoptiva como en la filiación por técnicas de reproducción humana asistida, el vínculo se determina por la manifestación de voluntad que se presta con anterioridad a la concepción.

10 Causa N $^{\circ} 36167 / 16$, Juzgado de Familia N 4 de La Plata, a cargo de la Dra. Silvia Andrea Mendilaharzo, del 6 de Marzo del año 2016. 
En la TRHA, el CONSENTIMIENTO se declara en dos instancias:

$1^{\text {a }}$ instancia: se presta ante el centro de salud interviniente, el cual debe renovarse cada vez que se efectúa una técnica. Esto es fundamental, sobre todo por los intentos que demandan estas prácticas y los cambios de las personas en su sentir más íntimo respecto a la autonomía procreacional. "ARTÍCULO 560.- Consentimiento en las técnicas de reproducción humana asistida. El centro de salud interviniente debe recabar el consentimiento previo, informado y libre de las personas que se someten al uso de las técnicas de reproducción humana asistida. Este consentimiento debe renovarse cada vez que se procede a la utilización de gametos o embriones".

El consentimiento es libremente revocable mientras no se haya producido la concepción en la persona o la implantación del embrión (conforme artículo $561 \mathrm{CC}$ y C).

$2^{\mathrm{a}}$ instancia: consentimiento que consta en el legajo que debe conformarse ante el Registro Civil (documento administrativo).

El artículo 562 ya citado define a la voluntad procreacional como fuente filiatoria y no al nacimiento. El vínculo filial que surge de estas para prácticas, conforma un lazo jurídico que nace de la voluntad acentuando el carácter social y cultural de la filiación.

En resumen, podemos decir que:

- El Consentimiento previo, libre e informado es la causa fuente de la filiación que nace del empleo de TRHA.

- Implica la manifestación de la Voluntad Procreacional.

- El mismo debe recabarse en el Centro de Salud que interviene, el que debe reunir los requisitos reglamentarios; aquí ponemos el acento pues la autoridad sanitaria aún no ha reglamentado al respecto.

- Debe ser protocolizado ante escribano público o certificado ante la autoridad sanitaria correspondiente a la jurisdicción.

- Puede revocarse mientras no se haya producido la concepción en la persona o la implantación del embrión.

- Debe renovarse cada vez que se utilicen los gametos o embriones. 
- Hasta tanto no estén en circulación los Formularios de Constatación de Partos en los que exista un campo destinado a dejar constancia del empleo de TRHA, lo hará el Oficial Público interviniente de puño y letra el profesional médico u obstétrica al certificar el nacimiento y el registrador en el Registro Civil a completar la planilla de datos para el labrado del acta.

Deberá adjuntarse copia certificada del Consentimiento, deberá protocolizarse ante escribano público o debe ser certificado ante la autoridad sanitaria correspondiente a la jurisdicción. El vínculo filial quedará constituido entre quien dio a luz y la persona que prestó en consentimiento previo, libre e informado.

Elartículo563 prevéelderechoasaberquesehanempleadoTRHA,pues estainformación debe constar en el Legajo Base(noasíen elacta deNacimiento).

Es importante el resguardo del legajo personal del consentimiento en la órbita de la Autoridad Sanitaria y a su vez el Registro de las Personas guarda un duplicado que sirva después del parto para la inscripción. Resulta inviable la guarda de los consentimientos por el registro, en todas las instancias de la práctica, pues como hemos dicho, un porcentaje muy bajo de ellas llega a término. Normalmente, toda pareja requiere varios intentos de prácticas hasta lograr el embarazo deseado. Carece de sentido sobrecargar al Registro con la toma de los consentimientos.

En nuestras sociedades la realidad y el planteo de los casos por los particulares nos sorprende, se anticipan y aceleran los cambios legislativos. Así, ya han sido dictados fallos vinculados a la gestación por sustitución, instituto expresamente excluido por el codificador.

Sin embargo, la tensión entre el derecho humano a la voluntad procreacional y el derecho humano al acceso integral a las TRHA sin ningún tipo de discriminación, significa comprender y dar una solución pues la única forma de garantizar eficazmente ese derecho, va a ser la gestación por sustitución.

Esta tensión ha llegado recientemente a un novedoso planteo: una acción colectiva referida a "gestación solidaria" de la Cámara de Apelaciones en lo Contencioso Administrativo y Tributario de la Ciudad Autónoma de Buenos Aires $(\mathrm{CABA})^{11}$ : revocó el rechazo in limine dispuesto en primera instancia y ordenó como medida cautelar "...al Registro del Estado Civil y

11 "Defensor del Pueblo de la de la Ciudad Autónoma de Buenos Aires (CABA) y otros c/ GCBA y otros s/ Amparo (Expediente $\mathrm{N}^{\circ}$ A1861/2017-0) del 4 de Agosto de 2017. 
Capacidad de las Personas que inscriba provisionalmente a los niños y niñas nacidos/ as por técnicas de reproducción humana asistida de alta complejidad realizados en el país, denominados de gestación solidaria, a favor de los comitentes con voluntad procreacional, conforme el consentimiento previo, libre e informado expresado por éstos, y sin emplazar como progenitora a la gestante que expresó previa y fehacientemente no tener voluntad procreacional. Asimismo, se ordena que sean debidamente incorporados los datos de la gestante en el legajo base -juntamente con la información que determina el art. 563, CCyC- a fin de respetar el derecho a la identidad de los niños y niñas pertenecientes a dicho colectivo".

Reiteramos, la realidad supera las previsiones legislativas, estaremos atentos a su resolución final en la justicia.

\section{CONCLUSIÓN.}

Para comprender el impacto que causan estos nuevos postulados en el instituto de la filiación, y a la luz de los derechos involucrados, resulta conveniente realizar una diferenciación entre el derecho a la filiación, el derecho a la identidad y el derecho a la verdad.

La Suprema Corte de la Provincia de Buenos Aires ${ }^{12}$ ha dicho en relación a las posturas que no distinguen estos conceptos:" Adviértase que al lado de la biológica existe otra verdad que no podrá ser ignorada: la verdad sociológica cultural y social que también hace a la identidad de la persona humana. La identidad filiatoria tiene también una perspectiva dinámica y presupone arraigo de vinculos paterno-filiales asumidos y recíprocamente aceptados por padre e hijo. La mentada verdad biográfica debe merecer amparo y respeto por la justicia. De esta manera, sucede que en los casos de posesiones de estado consolidado, no tiene por qué prevalecer un elemento biológico afectando una identidad filiatoria que no es su correlato" (autor citado, "Posesión de estado, filiación jurídica y realidad biológicas", en La Ley, 2004-E, pág. 1197) ${ }^{13}$.

Si lo interpretáramos de otro modo, el derecho a la ubicación biológica predominaría sobre el derecho protector de la infancia, pues debemos encontrar un equilibrio entre el derecho a la averiguación, al establecimiento de la verdad biológica, y el derecho de los niños y niñas a que se preserven sus relaciones familiares, conforme la dinámica familiar que los adultos responsables le han impuesto.

La familia debe ser entendida como el núcleo de quienes representen vínculos significativos en el desarrollo y protección de los niños y niñas.

12 Máximo Tribunal de Justicia de la Provincia de Buenos Aires.

13 Causa C. 101.726, “M. , J. F. contra M. , E.J. Filiación (Impugnación de paternidad)”. 
Mientras que el derecho a la filiación se traduce en la prerrogativa que tiene toda persona de contar con un emplazamiento completo, el derecho a la identidad, está integrado con el aspecto estático (elementos identificatorios como huellas digitales, fecha y lugar de nacimiento, nombre de los padres, prenombre y apellidos de la persona); y el aspecto dinámico (proyección social que se despliega durante la vida de la persona y comprende toda su historia personal, su biografía existencial, su estructura social y cultural).

A su vez, el derecho a conocer la verdad en relación a las técnicas de reproducción humana asistida se presenta una situación particular según expresa Kemelmajer "...en la fecundación asistida mal llamada 'heteróloga', con 'donante anónimo', un importante sector de la legislación comparada niega al niño la acción de filiación contra quien proporcionó el material genético, pero le acuerda el derecho a tener acceso a sus orígenes biológicos a partir del momento en que él adquiere madurez suficiente" 14.

En efecto, el caso "Odièvre" resuelto por el Tribunal Europeo de Derechos Humanos, se plantea el derecho de una persona que había sido adoptada (nacida mediante lo que en Francia se conoce como parto anónimo) y quería conocer sus orígenes, es en esta causa el Tribunal le niega este derecho y funda su decisión considerando que debió haberse diferenciado el derecho a conocer el origen del derecho a generar vínculos jurídicos ${ }^{15}$.

En esa dirección, el nuevo Código Civil y Comercial de la Nación ordenó el capítulo referido a las fuentes de filiación y las acciones que pueden entablarse, sin contar entre ellas con la acción autónoma de acceso a la verdad biológica. Sin embargo, la doctrina en Argentina si se manifiesta, ha de contestar con su necesidad aunque ello signifique renunciar a establecer vínculos jurídicos . ${ }^{16}$

Este análisis diferenciado permite comprender que además de vínculos jurídicos filiales que se corresponden con lo biológico, podemos encontrarnos con emplazamientos completos sustentados en el elemento volitivo, frente a la ausencia total o parcial del elemento genético.

14 Kemelmajer de Carlucci, Aída, “El derecho humano a conocer el origen biológico y el derecho a establecer vínculos de filiación. A propósito de la decisión del Tribunal Europeo de Derechos Humanos del 13/2/2003, en el caso Odièvre v. France", RDF 26-2004-77.

15 (Kemelmajer de Carlucci, ob. cit., p. 77).

16 Kemelmajer de Carlucci, Aída, Prólogo al libro de Gil Domínguez, Andrés; Famá, María Victoria; Herrera, Marisa, Derecho constitucional de familia, t. II, Ediar, Bs. As., 2006, P. XIII, Gil Domínguez, Andrés; Famá, María Victoria; Herrera, Marisa, Derecho constitucional de familia, t. II, Ediar, Bs. As., 2006, p. 814; Chechile, Ana María, "El derecho humano de acceder a la verdad biológica sin generar vínculos jurídicos", RDF 2006-III-162; Medina, Graciela, "Adopción y conocimiento de la verdad biológica. (El caso Odièvre de la Corte Europea)", LL 2003-E-1253; Krasnow, Adriana N., "El derecho de acceso a la verdad biológica no tiene límite en el tiempo", LL 2007-A-444). 
El presupuesto de la veracidad material, es necesario pero no suficiente para determinar el vínculo; en tanto con ese análisis limitado, puede llegar a prescindirse de las verdaderas relaciones e intenciones, lo cual claramente no es incompatible con un régimen de filiación guiado por los principios de interés superior del menor y la igualdad.

El tribunal citado, también ha dicho que el estado de familia es de orden público y que se rige por un conjunto de principios en que el orden social asienta su existencia; y en virtud de ello, considera que es deber de los Poderes Públicos (Estado) investigar lazos filiatorios cuando estos son desconocidos, creando lo que ha denominado tutela estatal de la identidad de origen de los individuos. ${ }^{17}$

En nuestras sociedades, el nacimiento determina la adquisición de la personalidad y esta es el atributo por el que el ordenamiento jurídico confiere a todo ser humano la capacidad general para ser sujeto in abstracto de derechos y obligaciones. Dicho atributo constituye la trama en la que se entrelazan los hilos de las restantes cualidades de estado civil. Estado civil en el que existe un interés público social pues se encuentra en juego el estado de "familia" y el deber del Estado de garantizar el emplazamiento filiatorio de los habitantes de la nación.

La agenda mundial y regional para el año 2030, nos insta a generar sistemas efectivos de identidad, a "proporcionar acceso a una identidad jurídica para todos ${ }^{18 "}$ y en esta cruzada el rol que le cabe en la protección del derecho a la identidad a los Registros Civiles es fundamental.

\section{REFERENCIAS}

Basset, Úrsula C. (16 de octubre de 2014). La democratización de la filiación asistida. La Ley, - LA LEY 2014-F, 609. Cita Online: AR/DOC/3594/2014.

Basset, Úrsula C. (14 de julio de 2015). El consentimiento informado y la filiación por procreación asistida en el Código Civil y Comercial. La Ley, Cita Online: AR/DOC/2099/2015.

Chechile, Ana María (2006). El derecho humano de acceder a la verdad biológica sin generar vínculos jurídicos, RDF 2006-III-162.

Corte Interamericana de Derechos Humanos, caso de las Hermanas Serrano

17 SCBA. A C U E R D O 17 de junio de 2015, causa C. 92,539, “De Angel, Obdulio José contra Angela Santina Actis Perino, viuda de Bruni. Petición de herencia".

18 Objetivos de Desarrollo Sostenible (ODS). Meta 16.9 Agenda 2030. 
Cruz vs. El salvador. Sentencia del 23 de noviembre de 2004.

Ferrari Gustavo y Mariana Manso (viernes 31 de julio de 2015). La triple filiación como ampliación de Derechos: el rol del Estado. Diario La Ley on line. Año IXXIX No 142, Buenos Aires, Argentina.

Gil Domínguez, Andrés; Famá, María Victoria y Herrera, Marisa. (2006). Derecho Constitucional de Familia, t. II, Buenos Aires, Argentina: Ediar, p. 814.

Kemelmajer de Carlucci, Aída (13 de febrero de 2003)."El derecho humano a conocer el origen biológico y el derecho a establecer vínculos de filiación. A propósito de la decisión del Tribunal Europeo de Derechos Humanos, en el caso Odièvre v. France", RDF 26-2004-77.

Kemelmajer de Carlucci, Aída (2006). Prólogo al libro de Gil Domínguez, Andrés; Famá, María Victoria; Herrera, Marisa, Derecho Constitucional de Familia, t. II, Buenos Aires, Argentina: Ediar, p. XIII.

Krasnow, Adriana N. El derecho de acceso a la verdad biológica no tiene límite en el tiempo, LL 2007-A-444.

Manso, Mariana (2016). El Registro Civil como garante de la desemejanza e intangibilidad de los cuerpos. La persona como centro de la actividad registral civil, su protección con el nuevo Código Civil y Comercial. Revista CALP edición especial por Nuevo CC y C. Octubre.

Medina, Graciela, “Adopción y conocimiento de la verdad biológica. (El caso Odièvre de la Corte Europea)", LL 2003-E-1253.

Pichardo Galán, José Ignacio, De Stéfano Barbero Matías y Martín-Chiappe M. Laura (enero - junio 2015). (Des)naturalización y elección: emergencias en la parentalidad y el parentesco de lesbianas, gays, bisexuales y transexuales. Revista de Dialectología y Tradiciones Populares, vol. LXX, n.o 1, pp. 187-203, ISSN: 0034-7981, ISSN: 1988-8457, doi: 10.3989/rdtp.2015.01.009.

SCBA. A C U E R D O 17 de junio de 2015, causa C. 92,539, "De Angel, Obdulio José contra Angela Santina Actis Perino, viuda de Bruni. Petición de herencia".

Sentencia SCBA del c9584.417,'LL. , J. A. contra J. , P. V. y L. , V.B. Impugnación de paternidad". 28 de mayo de 2014.

Fecha de recepción: 28 de agosto de 2017

Fecha de aceptación: 19 de setiembre de 2017 